\title{
Pseudoxanthoma elasticum presenting with myocardial infarction
}

\author{
Alistair K B Slade, Roy M John, R H Swanton
}

\begin{abstract}
A 31 year old man presented with an anterior myocardial infarction. He had a history of recurrent gastrointestinal bleeding of obscure cause since childhood and peripheral vascular disease. $A$ clinical diagnosis of the type 1 dominant form of pseudoxanthoma elasticum was supported by histological data from skin biopsy.
\end{abstract}

Nearly all cases of myocardial infarction in middle aged men in the UK are caused by idiopathic atherosclerotic obstructive coronary artery disease. Premature coronary artery disease is frequently associated with hyperlipidaemia and diabetes mellitus but inherited abnormalities of connective tissue are a rare cause. We report a case of pseudoxanthoma elasticum presenting with a myocardial infarction.

\section{Case report}

A 31 year old white man presented to his general practitioner in January 1989 with a history of an unprovoked episode of prolonged anterior chest pain ten days before. An electrocardiogram showed changes of a recent anterior myocardial infarction. He was referred to hospital for outpatient assessment.

A past history of recurrent gastrointestinal bleeding and intermittent claudication of the right leg was elicited. Gastrointestinal bleeding had commenced at the age of 12 years with bouts of melaena requiring blood transfusions. Endoscopy of the upper gastrointestinal tract was normal and biopsy of an area of abnormal gastric mucosa showed only histological features consistent with gastric erosion. He continued to be troubled by repeated epigastric pains and melaena and was admitted to hospital several times for repeated investigations that failed to show a definite cause. Intermittent claudication affecting the right calf muscle appeared during the 12 months before his present episode and produced claudication pain at $600-800$ yards $(540-720 \mathrm{~m})$. There was no family history of arterial disease, hypertension, or recurrent gastrointestinal bleeds. He smoked 30 cigarettes per day and alcohol intake was moderate.

There were no peripheral pulses below the femoral arteries on either side but there was no evidence of chronic ischaemia in the legs.
He was normotensive (150/80 $\mathrm{mm} \mathrm{Hg}$ ). Retinal examination showed florid angioid streaks. He had small areas of pseudoxanthomatous skin on either side of his neck. The electrocardiogram confirmed changes of a $Q$ wave anteroseptal myocardial infarction. Chest $x$ ray showed mild cardiomegaly but no cardiac failure. Echocardiography showed an area of anteroapical hypokinesia without mural thrombus and fair overall left ventricular function. The lipid profile was normal. He was treated with $50 \mathrm{mg}$ daily of atenolol and discharged with arrangements for an exercise test and clinic review. Six days later recurrence of chest pain led to admission to hospital. There was no objective evidence of new myocardial ischaemia or infarction. He was referred for urgent coronary angiography.

Cardiac catheterisation showed anteroapical left ventricular akinesia. The left anterior descending artery was occluded distal to the first septal branch (fig 1) and the distal vessel filled retrogradely from the right coronary artery which was dominant and normal. A small circumflex vessel was normal. The left ventricular ejection fraction was estimated to be $33 \%$ by radionuclide ventriculography.

The patient's cardiac symptoms settled with medical treatment and he was discharged on nitrates, diuretics, and captopril. Subsequent vascular surgical intervention by way of percutaneous angioplasty for a tight stenosis of the right common femoral artery was successful and greatly improved his claudication pain. Genetic counselling has been given.

\section{Dicussion}

Pseudoxanthoma elasticum is a rare inherited disorder of elastic tissue (incidence 1:160 000). ${ }^{1}$ There are at least two dominant and two recessive inheritance patterns of the disease. ${ }^{2}$ This patient has the type 1 dominant form with predominant vascúlar and eye changes.

Pseudoxanthoma elasticum is expressed clinically in three main areas: the skin, the eye, and the cardiovascular system. Widespread involvement of the muscular arteries also produces haemorrhagic symptoms in almost every organ system. The degree to which the various systems are affected is highly variable. Haemorrhage and cardiovascular complications usually bring patients to medical attention. The cardiovascular manifestations reported include peripheral vascular disease, coronary artery disease, 


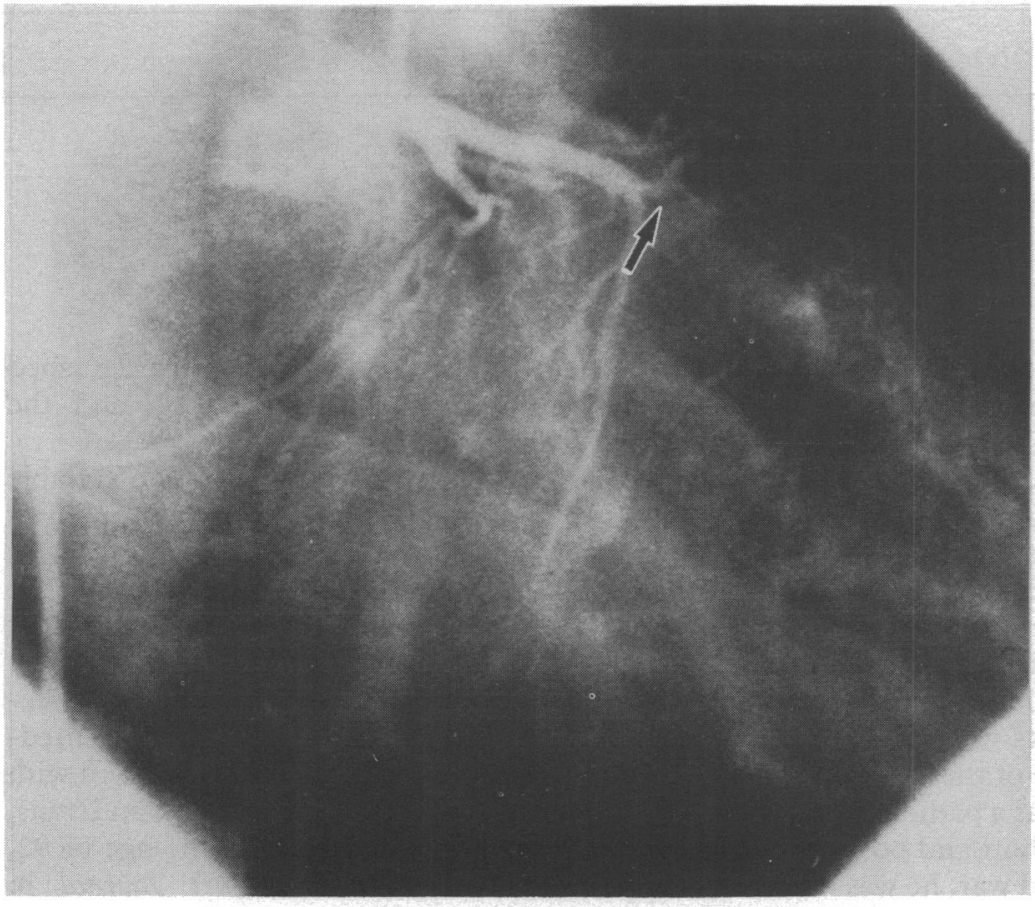

Figure 1 Left coronary angiogram in the right anterior oblique view showing occlusion of the left anterior descending artery distal to the first septal branch (arrow).

renovascular hypertension, ${ }^{3}$ restrictive cardiomyopathy, ${ }^{4}$ and an association with mitral valve prolapse. ${ }^{5}$ The basic abnormality is not clear but is thought to involve degeneration of elastic tissue. Pathologically, disorganisation with fragmentation and clumping and calcification of elastic fibres in muscular arteries and endocardium has been noted in a necropsy study by Mendelsohn et al. ${ }^{6}$ This study of three patients with pseudoxanthoma elasticum and congestive cardiac failure also showed considerable involvement of the atrial endocardium with extensive atrial calcification in one case.

Angina is well recognised and Carlborg et al reported angina pectoris in 15 of 29 patients with pseudoxanthoma elasticum at a mean age of 38 years. ${ }^{7}$ However, myocardial infarction is thought to be rare. Coronary artery disease was reported in childhood ${ }^{8}$ and coronary bypass grafting successfully undertaken in an 18 year old girl. ${ }^{9}$

Our patient had the classic features of pseudoxanthoma elasticum and histological examination of a skin biopsy specimen (fig 2) confirmed the diagnosis. The patient is suitable for coronary artery bypass grafting if angina becomes limiting. Retinal fluoroscopic angiography is necessary for identification of possible vessels liable to haemorrhage that require laser photocoagulation. Fortunately, there has been no recent recurrence of gastrointestinal haemorrhage but a bleed that is

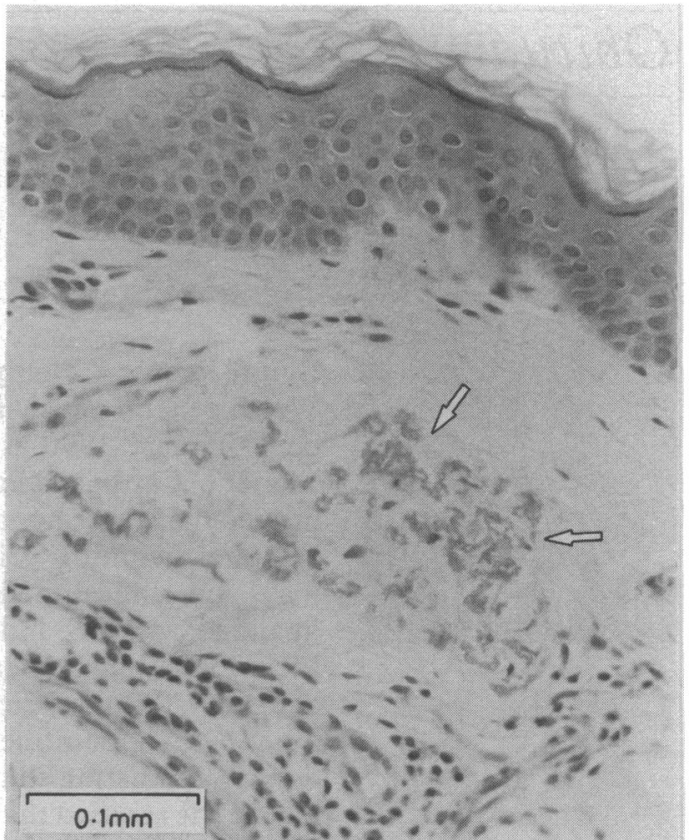

Figure 2 Histology of skin biopsy. Haematoxylin and oosin stain showing the swollen and clumped elastic fibres (arrows) in the dermis.

difficult to control could be treated by gastric arterial embolisation. ${ }^{10}$

In our patient there was a rare but important cause for coronary artery disease; young patients with a history of recurrent gastrointestinal bleeds presenting with vascular occlusive complications should be carefully examined for such rare inherited forms of connective tissue diseases.

We thank Dr T Matthews of Battle Hospital for help with the histological data.

1 Engelman MW, Fliegelman MT. Pseudoxanthoma elasticum. Cutis 1978;21:837-40.

2 Pope FM. Historical evidence for the genetic heterogeneity of pseudoxanthoma elasticum. Br J Dermatol 1975; 92:493-509.

3 McKusick VA. Pseudoxanthoma elasticum. In: Heritable disorders of connective tissue. St Louis: CV Mosby, 1972:475-520.

4 Navarro-Lopez F, Llorian A, Ferre-Roca O, Betriu A, Sanz $G$. Restrictive cardiomyopathy in pseudoxanthoma elasticum. Chest 1980;78:113-5.

5 Lebwohl MG, Distefano D, Prioleau PG, Uram M, Yannuzzi LA, Fleischmajer R. Pseudoxanthoma elasticum and mitral valve prolapse. $N$ Engl J Med 1982;307:228-31.

6 Mendelsohn G, Bulkley BH, Hutchins GM. Cardiovascular manifestations of pseudoxanthoma elasticum. Arch Pathol Lab Med 1978;102:298-302.

7 Carlborg U, Ejrup B, Gronblad E, et al. Vascular studies in pseudoxanthoma elasticum and angiod streaks. Acta Med Scand 1959;166 (suppl 350):1-84.

8 Schachner L, Young D. Pseudoxanthoma elasticum with severe cardiovascular disease in a child. Am J Dis Child 1974;127:571-5.

9 Bete JM, Banas JS, Moran J, Pinn V, Levine HJ. Coronary artery disease in an 18 year old girl with pseudoxanthoma artery disease in an 18 year old girl with pseudoxanthoma elasticum: succes

10 Cunningham JR, Lippman SM, Renie WA, Francomano CA, Maumenee IH, Pyeritz RE. Pseudoxanthoma elasticum: treatment of gastrointestinal haemorrhage by ticum: treatment of gastrointestinal haemorrhage by arterial embolisation and observations on autosomal dominant inhe
147:168-73. 